\title{
DESIGNING AN EMPOWERMENT MODEL FOR IRANIAN HEALTH CENTRE MANAGERS: A COMPREHENSIVE STUDY
}

\author{
Fatemeh Yousef Yaghoobi (PhD) 1, Leila Riahi (PhD) 2, Seyed Jamaleddin Tabibi (PhD) 3, \\ Mahmood Mahmoodi Majdabadi Farahani (PhD) 4
}

1. Department of Health Services Management, Science and Research Branch, Islamic Azad University, Tehran, Iran

2. Assistant Professor, Department of Health Services Management, Science and Research Branch, Islamic Azad University, Tehran, Iran

3. Professor, Department of Health Services Management, Science and Research Branch, Islamic Azad University, Tehran, Iran

4. Professor, Department of Health Services Management, Science and Research Branch, Islamic Azad University, Tehran, Iran

Correspondence: I.riahi@srbiau.ac.ir

\begin{abstract}
\section{OBJECTIVES}

Empowering managers plays a crucial role in developing the capabilities and competencies of individuals to improve the continuous performance of health centre organisations. The purpose of this study is to design a model of empowerment of health centre managers in Iran during 2018-2019.
\end{abstract}

\section{DESIGN}

In this applied, exploratory, and cross-sectional study, human resource empowerment components were extracted by reviewing the literature and interviewing subject specialists. Then, the conceptual model of the research was designed, and the questionnaire was formulated and validated. Data were collected by filling out a questionnaire from a total of 416 managers of health centres selected by stratified random sampling. The collected data were analyzed using descriptive statistics and confirmatory and exploratory factor analysis.

\section{RESULTS}

In the final model of empowerment of health centre managers, five factors were identified as effective factors. The standardised regression coefficients among the contextual, self-efficacy, managerial, organisationalvalue, and psychological factors with empowerment were $0.98,0.95,0.92,0.90$, and 0.76 , respectively. The results of confirmatory factor analysis indicate the suitability of the final model of health centre managers' empowerment.

\section{CONCLUSIONS}

Due to the influence of contextual, self-efficacy, managerial, organisational-value, and psychological factors in the model approved in this study, the health system senior managers can have a systemic approach to issues. In addition, they can improve managers' abilities by employing a continuous self-assessment system in health centres, applying the proposed model, improving administrative infrastructure and working environment, paying attention to organisational culture, reward system, participatory management, information sharing, continuous training, and modeling.

\section{KEYWORDS}

Empowerment, Empowerment Model, Health Centres, Health Management 
INTRODUCTION

Empowering managers is one of the most effective techniques for enhancing employee productivity and making optimal use of their capabilities and capabilities in organisational goals. It is an important strategy regarding its potential and beneficial functions in the organisation, such as increased commitment, better decision making, improved service quality, creativity, innovation, and increased job satisfaction. [1] Empowerment plays a crucial role in developing the abilities and competencies of individuals to improve the continuous performance of health centre organisations. [2] Ellis \& Hartley [3] have emphasized that no profession can provide good quality services unless its members feel empowered and in control of their actions. Clearly, the presence of empowered managers is one of the factors contributing to the success of health centre providers. Upgrading these capabilities can be effective in directing resources and making maximum use of them.

The life and survival of the health centre system largely depend on different abilities, skills, knowledge, and expertise of human resources, especially the managers in that system. The more capable managers are, the more they can contribute to improving the performance level of the organisation. According to some experts, empowering managers and staff in the health system is a set of systems, methods, and actions that develop the capabilities and competencies of individuals to enhance the productivity, growth, and prosperity of the organisation and human resources. [4] Many writers and researchers have emphasized the key role of empowerment in promoting and sustaining human resource performance. Empowerment is removing barriers, creating a commitment to the organisation's goals in employees, creating a sense of risk, and encouraging creativity and innovation in individuals to accept greater responsibility and accountability for results. Empowering managers and employees can be one of the most important factors for making managers, employees, and organisations more efficient. [5] According to Robbins et al. [6], individual elements, intrinsic motivation, perception and commitment, environmental factors, job structure, the delegation of power or authority, and the sharing of resources and information are among the factors influencing empowerment.
Given the scarcity of resources in the health system and factors such as the need to prevent waste of limited resources, the optimal use of existing facilities, improving the job performance of employees and the efficiency and effectiveness of the organisation, the provision of highquality services to the community, "accountability," "social justice", and "public satisfaction" are issues that cannot be achieved except with employee empowerment, especially health system managers. In addition, as health policymakers and senior executives in recent years have paid more attention to managerial positions and capabilities for managers, especially managers of health centres, more research is needed to design a model for empowering managers of health centres.

So, the main goal of this research which can be known as its novelty is to investigate the effect of various factors on the empowerment of health centre managers in Iran by designing a comprehensive model.

\section{METHODS}

This applied, exploratory, and cross-sectional study was conducted to design a model of empowerment of health centre managers in Iran during 2018-2019. The statistical population consisted of all managers of the health centres at the operational level, affiliated with Medical Sciences Universities of East Azerbaijan, West Azerbaijan and Ardebil provinces from Iran. The study was conducted in five phases for two years:

In the first phase, the topic was examined using desk research, literature review, and search of multiple databases from 1990 to 2019. A total of 10 valid human resources management models were identified: (Bandura [7], Faulkner and Laschinger [8], Konczak et al. [9], Kuokkanen and Katajisto [10], Vogt \& Murrell [1 1], Spreitzer [12], Mallak \& Kurstedt [13], Melhem [14], Cho et al. [15], and Eskandari [16]). Initial components influencing the managers' empowerment were extracted through a comparative matrix and described in Table 1.

The components extracted through the comparative matrix of the models under study were reviewed and validated through interviews with national health experts, managers, and specialists. Fig. 1 illustrates the conceptual model of empowerment of health centre managers derived from this process. 


\begin{tabular}{|c|c|c|c|c|c|c|c|c|c|c|c|}
\hline Row & Empowerment Model & 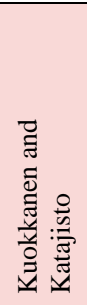 & 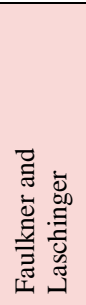 & 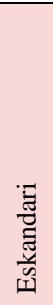 & 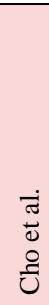 & $\frac{\Xi}{\bar{\Xi}}$ & 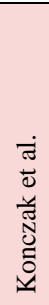 & 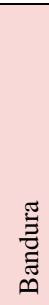 & 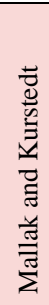 & 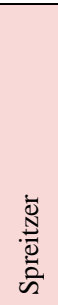 & 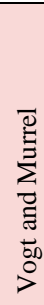 \\
\hline 1 & Continuous training & * & * & * & & * & & * & * & & * \\
\hline 2 & Guidance and support & * & * & * & * & * & & * & * & & * \\
\hline 3 & Access to resources & * & * & . & & * & * & * & * & * & * \\
\hline 4 & Participatory management & * & * & * & * & * & * & * & * & & * \\
\hline 5 & Effectiveness & * & * & * & & & & * & * & * & \\
\hline 6 & Self-Determination & * & * & * & & * & & * & * & * & \\
\hline 7 & Competence & * & * & * & & & & * & * & * & \\
\hline 8 & Meaningfulness & * & * & * & & & & * & * & * & \\
\hline 9 & Organisational culture & * & & * & & & & * & * & * & * \\
\hline 10 & Organisational mission and performance & * & * & * & & * & * & * & & * & * \\
\hline 11 & Reward system & & * & * & & & 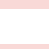 & * & * & * & * \\
\hline 12 & Emotional arousal & * & * & * & * & & 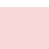 & * & * & * & \\
\hline 13 & Delegation of authority & * & * & * & & * & * & * & * & . & * \\
\hline 14 & Delegation of responsibility & * & * & & & * & * & * & * & & * \\
\hline 15 & Positive emotional encouragement and support & * & * & * & * & & & * & * & * & * \\
\hline 16 & Modeling & * & * & 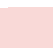 & & & * & * & * & & \\
\hline 17 & Having successful experiences & * & * & * & 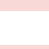 & * & 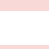 & * & * & * & * \\
\hline 18 & Responsibility & * & * & * & * & * & * & * & * & * & * \\
\hline 19 & Autonomous decision-making & * & * & * & 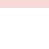 & * & * & * & * & * & * \\
\hline 20 & Information sharing & * & * & * & * & * & * & * & * & * & \\
\hline 21 & Capacity building & * & & * & * & & * & * & * & * & * \\
\hline 22 & Consulting & * & * & 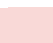 & & 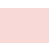 & * & * & * & & * \\
\hline 23 & Dynamic organisational structure & * & * & * & * & * & * & * & * & * & * \\
\hline 24 & Humility & * & * & & * & & & * & 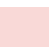 & * & \\
\hline 25 & Altruism & * & * & & * & & & * & & * & \\
\hline 26 & Intuition & * & * & & * & & & * & & * & \\
\hline 27 & Trust & * & * & * & * & * & & * & & * & \\
\hline 28 & Commitment & * & & * & * & & & * & & * & \\
\hline 29 & Job design & * & * & * & & * & * & * & * & * & * \\
\hline 30 & Having career capabilities & * & * & * & & * & * & * & 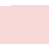 & * & * \\
\hline 31 & Having professional skills & * & * & * & & * & * & * & & * & * \\
\hline 32 & Motivational attitude toward work & * & * & * & & & 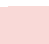 & * & * & * & * \\
\hline 33 & Challenging attitude toward working & * & * & * & & * & * & * & * & * & * \\
\hline 34 & Organisational climate & * & & * & & & * & * & * & * & * \\
\hline 35 & Style of leadership & * & * & * & * & * & * & * & * & & * \\
\hline 36 & Providing facilities & * & * & & & * & * & * & * & * & * \\
\hline 37 & Structural & * & * & * & * & * & * & * & * & * & * \\
\hline 38 & Access to information & * & * & * & * & * & * & * & * & * & \\
\hline 39 & Group belongingness & * & * & * & * & & & * & & & * \\
\hline 40 & Doing teamwork & * & * & * & & & & * & & & * \\
\hline 41 & Using knowledge and managerial experien & * & & * & & * & & * & & * & * \\
\hline 42 & Self-Esteem & * & * & * & & * & & * & * & * & \\
\hline
\end{tabular}




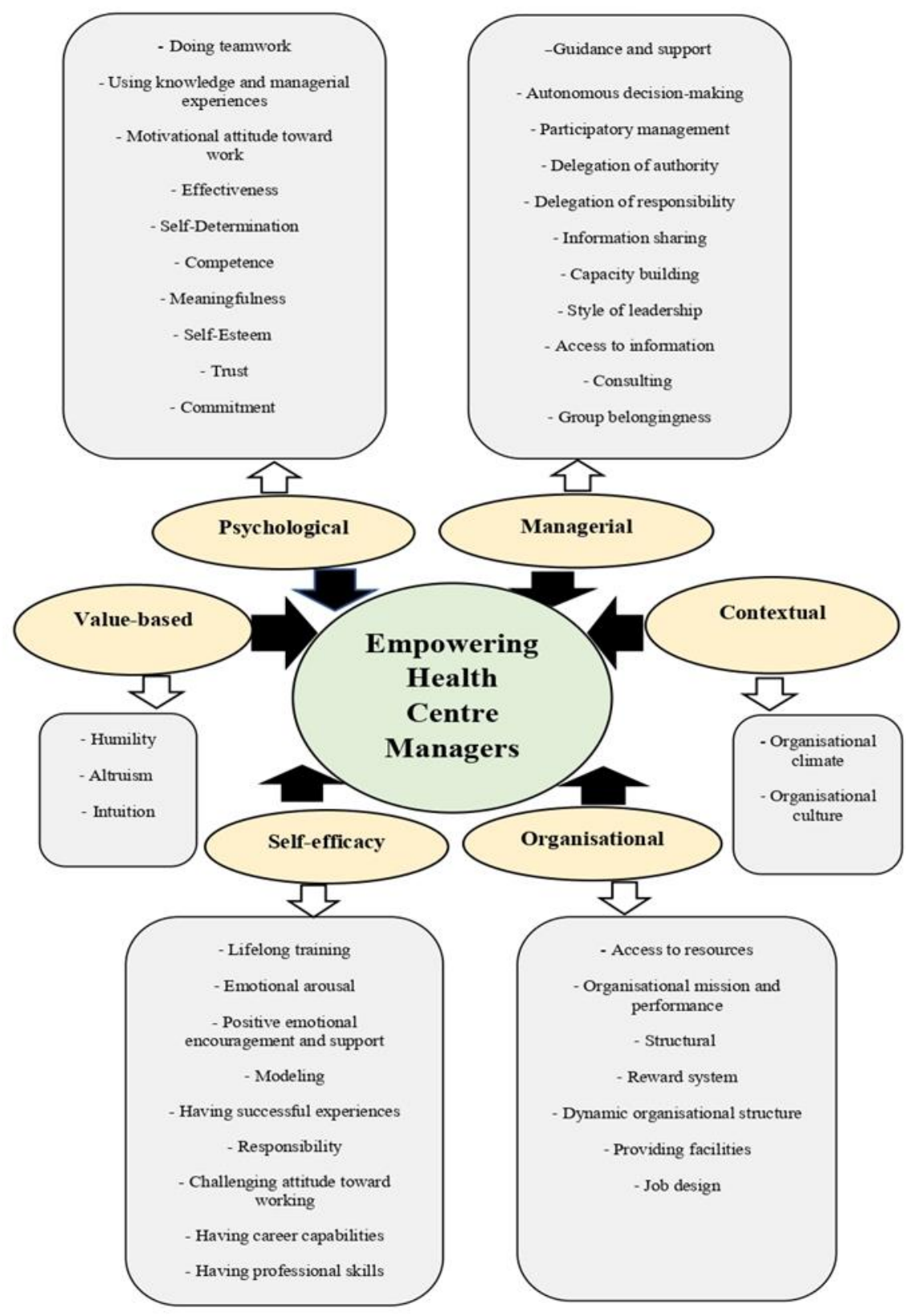

In the second stage, the initial researcher-made questionnaire with 42 components in 6 dimensions (psychological, organisational, managerial, self-efficacy, contextual, and value) was designed with 42 main items, and its validity and reliability were assessed. Besides, the content validity ratio (CVR) and the content validity index (CVI) were evaluated using the judgment of a panel of experts. Several items whose CVR was less than 0.42 (based on the number of experts) and their CVI was less than 0.79 were also eliminated; overlapping components were merged. Based on the results, the number of components was reduced to 37 items, and thus the questionnaire items were 37. The items of the Likert five-point questionnaire were scored from "very low" (score 1) to "very high" (score 5). In this questionnaire, items of some of the variables were two-part, and some three-part, whose scores were calculated in one main item. The reliability of the questionnaire was calculated by Cronbach's alpha (0.96) method using internal consistency methods.

In the third phase, before starting the field study, the sample size was determined. For this purpose, since this study used factor analysis and structural equation modeling and as some researchers suggest 5 to 10 samples per variable, so the sample size obtained from the provinces were chosen to be 10 times the number of components using stratified 
random sampling. Since the number of the health centres in East and West Azerbaijan were two times that of health centres in Ardebil province, therefore, the sample size was constituted of $40 \%$ samples from East Azerbaijan, $40 \%$ samples from West Azerbaijan and $20 \%$ samples from Ardebil.

One of the criteria for entering the subjects in this study is employed in the management position of the health centre at sampling time, and their desire to participate in answering the questionnaire, and the criteria for excluding subjects was their disconnection from the University of Medical Sciences for any reason or unwillingness to participate in the study. Moreover, considering the probability of a drop in completing the questionnaire, a questionnaire was distributed among the managers of the face-to-face health centres after the researcher had provided explanations about the research objectives, the confidentiality of information, and their consent to participate in the study. 416 completed questionnaires were collected, and 14 incomplete questionnaires were excluded from the study.

In the fourth phase, the collected data were analyzed using SPSS 22 software. Exploratory factor analysis (EFA) was used to determine the factors affecting the empowerment of health centre managers in different dimensions.

In the fifth phase, the results of the EFA obtained from the fourth step were validated using the confirmatory factor analysis (CFA) method and AMOS 24 software. Additionally, the results of CFA were evaluated and validated using fit indices.

\section{RESULTS}

According to the demographic data of the managers of the health centres studied (Table 2), the highest frequency among the 416 respondents was 252 males (61\%). The highest frequency was in the age group 41-50 with 176 $(42 \%)$ subjects. The highest level of education was in postgraduate and professional doctorate with 225 (54\%) subjects. The highest work experience was in the 11-20 years' age group with 201 (48\%) subjects.

Prior to EFA, test accuracy indices were evaluated to determine the factors affecting the empowerment of health centre managers. Assuming the normality of the study population, the KMO index (0.960) indicates the adequacy of sample size and the significance of Bartlett's test for sphericity $(P<0.001)$.

Based on the results of EFA, five main factors with eigenvalues greater than 1 were extracted as influencing factors on empowerment. Overall, these factors explained $56.807 \%$ of the total variance (Table 3 ).

Varimax rotation was used for better alignment. The 37 main items related to the 37 components of empowerment of health centre managers were classified into five main factors. Each of these factors was named after considering the content of the items and taking advantage of the theoretical foundations and opinions of the professors and experts. Table 4 presents the results of EFA in extracting the factors and naming them along with the factor loadings of the factors affecting the empowerment of health centre managers.

TABLE 2. DEMOGRAPHIC INFORMATION RELATED TO MANAGERS OF HEALTH CENTRES STUDIED

\begin{tabular}{llll} 
& & & \\
VARIABLE & VARIABLE LEVELS & FREQUENCY & PERCENTAGE \\
\hline \multirow{3}{*}{ Sex } & Male & 252 & 61 \\
& Female & 164 & 39 \\
\cline { 2 - 4 } & Total & 416 & 100 \\
\hline \multirow{2}{*}{ Age } & $20-30$ & 22 & 5 \\
& $31-40$ & 168 & 41 \\
& $41-50$ & 176 & 42 \\
& $>50$ & 50 & 12 \\
\hline
\end{tabular}




\begin{tabular}{llll}
\cline { 2 - 3 } & Total & 416 & 100 \\
\hline \multirow{4}{*}{ Marriage status } & Married & 378 & 91 \\
& Unmarried & 38 & 9 \\
\cline { 2 - 4 } & Total & 416 & 100 \\
\hline \multirow{4}{*}{ Level of education } & Associate degree & 4 & 1 \\
& BA & 181 & 44 \\
& MA and professional doctorate & 225 & 54 \\
& Ph.D. & 6 & 1 \\
\cline { 2 - 4 } & Total & 416 & 100 \\
\hline \multirow{3}{*}{ Length of service } & $1-10$ & 76 & 18 \\
& $11-20$ & 201 & 48 \\
& $21-30$ & 135 & 33 \\
& $31-40$ & 4 & 1 \\
\cline { 2 - 4 } & Total & 416 & 100 \\
\hline
\end{tabular}

TABLE 3. EIGENVALUES AND EXPLAINED VARIANCE OF THE FACTORS EXTRACTED FROM EFA

\begin{tabular}{|c|c|c|c|c|c|c|}
\hline \multirow{2}{*}{$\begin{array}{l}\frac{0}{U} \\
\frac{0}{0}\end{array}$} & \multicolumn{3}{|c|}{ Extraction Sums of Squared Loading } & \multicolumn{3}{|c|}{ Rotation Sums of Squared Loading } \\
\hline & $\begin{array}{l}\text { Eigenvalues } \\
\text { Total }\end{array}$ & $\begin{array}{l}\% \text { of } \\
\text { Variance }\end{array}$ & $\begin{array}{l}\text { Cumulative } \\
\%\end{array}$ & $\begin{array}{l}\text { Eigenvalues } \\
\text { Total }\end{array}$ & $\begin{array}{l}\% \text { of } \\
\text { Variance }\end{array}$ & $\begin{array}{l}\text { Cumulative } \\
\%\end{array}$ \\
\hline 1 & 15.256 & 41.232 & 41.232 & 6.066 & 16.396 & 16.396 \\
\hline 2 & 2.258 & 6.103 & 47.334 & 4.261 & 11.516 & 27.912 \\
\hline 3 & 1.298 & 3.507 & 50.841 & 4.183 & 11.306 & 39.219 \\
\hline 4 & 1.161 & 3.137 & 53.978 & 3.395 & 9.176 & 48.394 \\
\hline 5 & 1.047 & 2.828 & 56.807 & 3.113 & 8.413 & 56.807 \\
\hline
\end{tabular}

TABLE 4: RESULTS OF EXPLORATORY FACTOR ANALYSIS IN EXTRACTING FACTORS AND NAMING THEM WITH FACTOR LOADINGS OF COMPONENTS

\begin{tabular}{llll}
\hline FACTOR & COMPONENT & QUESTION & FACTOR \\
& Responsibility & CODE & LOAD \\
\hline \multirow{3}{*}{ Self-efficacy } & Using knowledge and managerial experiences & Q2 & 0.707 \\
& Continuous training & Q20 & 0.701 \\
& Challenging attitude toward working & Q26 & 0.698 \\
& & & 0.688
\end{tabular}




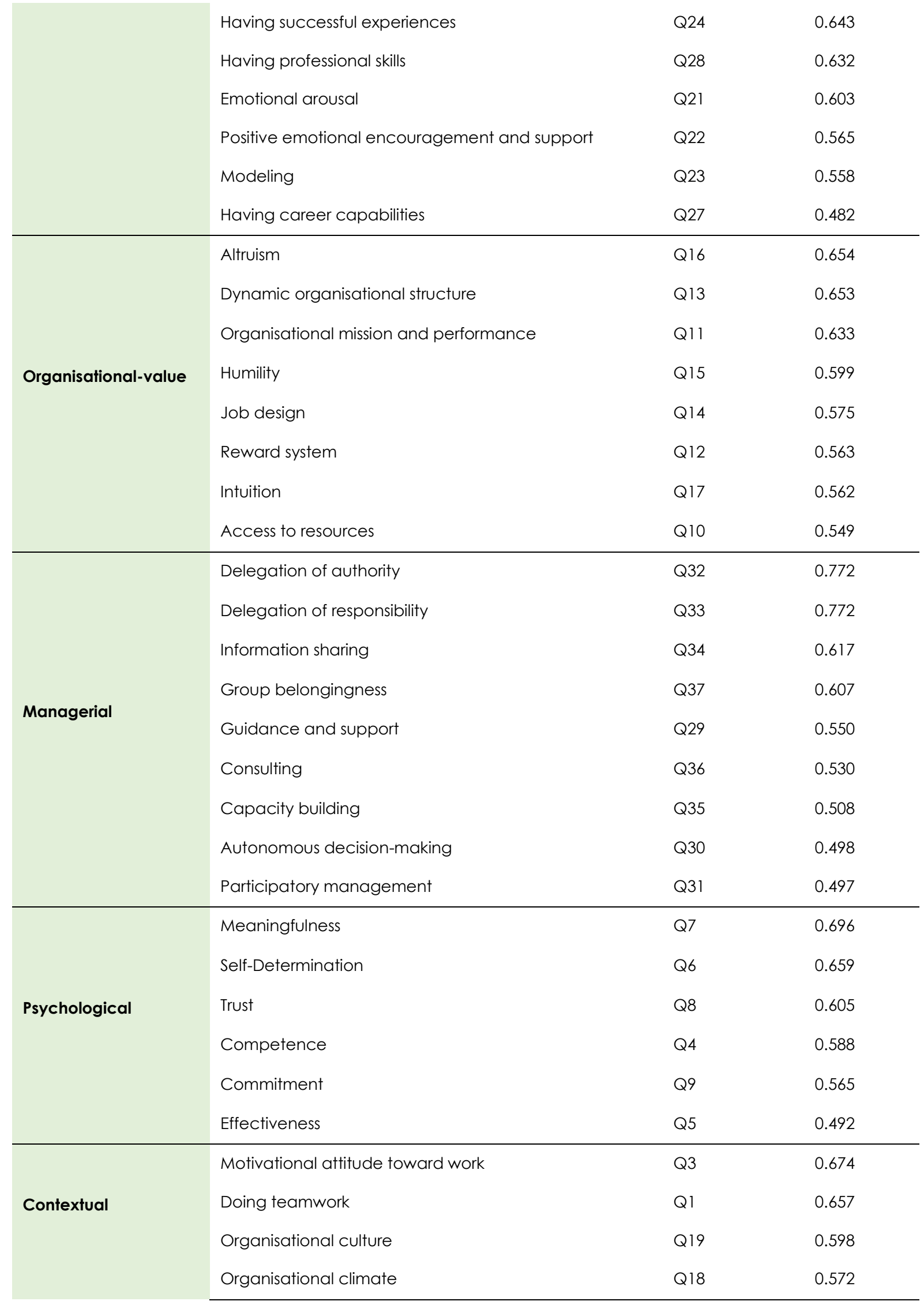


CFA was used to confirm the results of the EFA. Fig. 2 shows the CFA model of factors affecting the empowerment of health centre managers based on standardised coefficients.

Standardised regression coefficients were used to compare the effects of five factors of self-efficacy, organisational-value, managerial, psychological, and contextual on the empowerment of health centre managers, which are summarised in Table 5.

Based on CFA results, standardised regression coefficients were obtained $0.98,0.96,0.92,0.90$, and 0.76 , respectively, between contextual, self-efficacy, managerial, organisational-value, and psychological factors, with the empowerment of health centre managers $(P<0.001)$.
Table 6 presents the standardised regression coefficients of components affecting the empowerment of health centre managers based on CFA.

Based on confirmatory factor analysis, standardised regression coefficients of all 37 components related to the main factors (i.e., self-efficacy, organisational-value, managerial, psychological, and contextual) affecting the empowerment of health centre managers were significant at 37 main items at $\mathrm{P}<0.001$ and all components were confirmed.

CFA results were evaluated based on multiple fit indices, indicating the appropriateness of the final model of empowerment of health centre managers (Table 7).

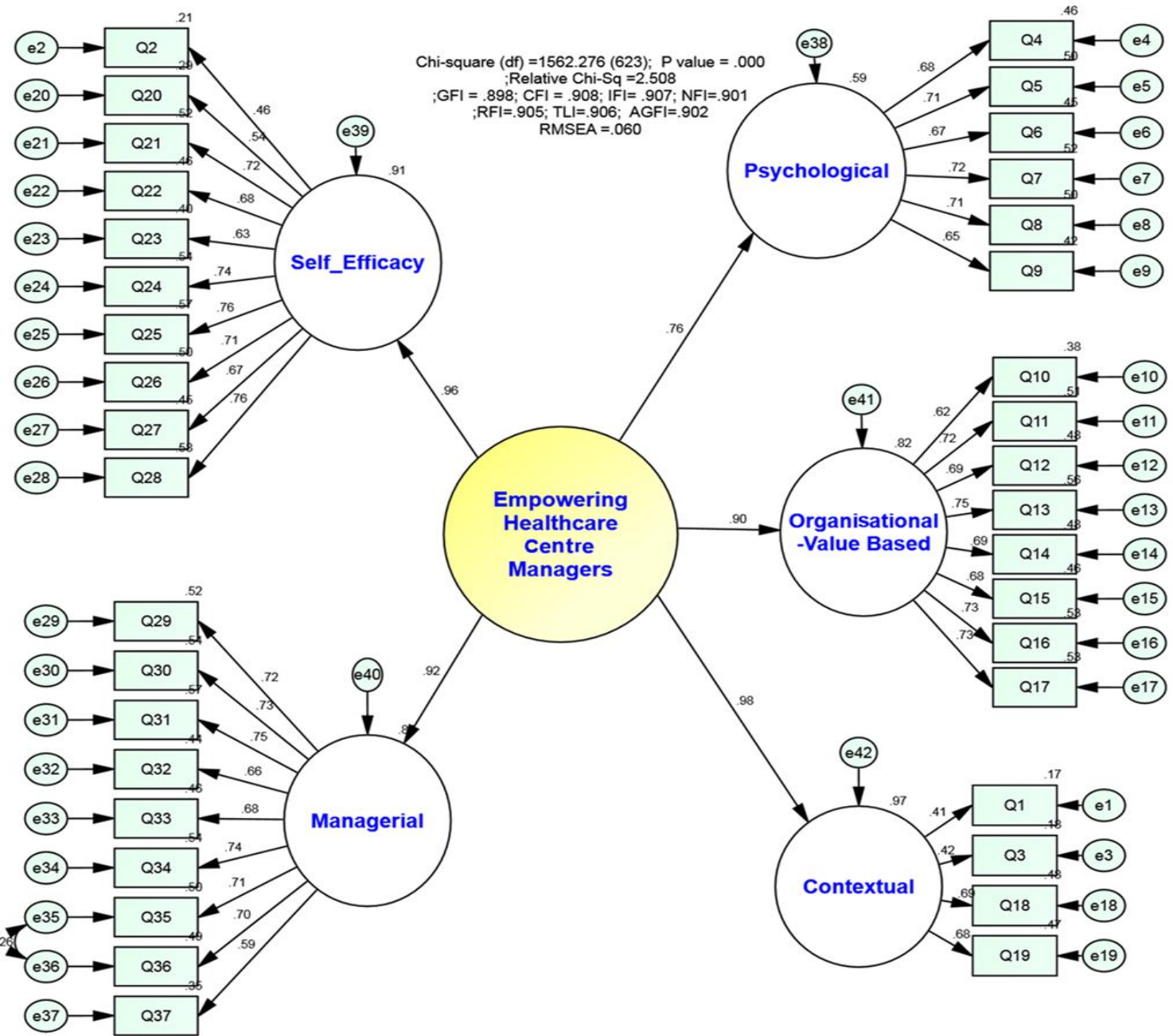


TABLE 5. STANDARDISED REGRESSION COEFFICIENTS FACTORS AFFECTING THE EMPOWERMENT OF HEALTH CENTRE MANAGERS

\begin{tabular}{|c|c|c|c|c|c|}
\hline $\begin{array}{l}\text { Independent } \\
\text { Variable }\end{array}$ & Dependent Variable & $\begin{array}{l}\text { Standard } \\
\text { regression } \\
\text { coefficient }\end{array}$ & $t$ & P-value & Status \\
\hline Self-efficacy Factor & $\begin{array}{l}\text { empowerment of } \\
\text { health centre } \\
\text { managers }\end{array}$ & 0.956 & 10.969 & 0.001 & Confirmed \\
\hline $\begin{array}{l}\text { Organisational- } \\
\text { value Factor }\end{array}$ & $\begin{array}{l}\text { empowerment of } \\
\text { health centre } \\
\text { managers }\end{array}$ & 0.905 & 9.755 & 0.001 & Confirmed \\
\hline Managerial Factor & $\begin{array}{l}\text { empowerment of } \\
\text { health centre } \\
\text { managers }\end{array}$ & 0.925 & 10.932 & 0.001 & Confirmed \\
\hline $\begin{array}{l}\text { Psychological } \\
\text { Factor }\end{array}$ & $\begin{array}{l}\text { empowerment of } \\
\text { health centre } \\
\text { managers }\end{array}$ & 0.765 & 8.326 & 0.001 & Confirmed \\
\hline Contextual Factor & $\begin{array}{l}\text { empowerment of } \\
\text { health centre } \\
\text { managers }\end{array}$ & 0.985 & 7.322 & 0.001 & Confirmed \\
\hline
\end{tabular}

TABLE 6: STANDARDISED REGRESSION COEFFICIENTS OF COMPONENTS AFFECTING THE EMPOWERMENT OF HEALTH CENTRE MANAGERS

\begin{tabular}{|c|c|c|c|c|c|c|}
\hline FACTOR & COMPONENT & $\begin{array}{l}\text { QUESTION } \\
\text { CODE }\end{array}$ & $\begin{array}{l}\text { STANDARD } \\
\text { REGRESSION } \\
\text { COEFFICIENT }\end{array}$ & $\mathbf{T}$ & $\begin{array}{l}\text { P- } \\
\text { VALUE }\end{array}$ & STATUS \\
\hline \multirow{9}{*}{ Self-efficacy } & Responsibility & Q25 & 0.756 & 15.104 & 0.001 & Confirmed \\
\hline & Using knowledge and & & 0.463 & 9.156 & 0.001 & Confirmed \\
\hline & $\begin{array}{l}\text { managerial } \\
\text { experiences }\end{array}$ & Q2 & & & & \\
\hline & Continuous training & Q20 & 0.536 & 10.620 & 0.001 & Confirmed \\
\hline & $\begin{array}{l}\text { Challenging attitude } \\
\text { toward working }\end{array}$ & Q26 & 0.709 & 14.137 & 0.001 & Confirmed \\
\hline & $\begin{array}{l}\text { Having successful } \\
\text { experiences }\end{array}$ & Q24 & 0.737 & 14.708 & 0.001 & Confirmed \\
\hline & $\begin{array}{l}\text { Having professional } \\
\text { skills }\end{array}$ & Q28 & 0.763 & 15.255 & 0.001 & Confirmed \\
\hline & Emotional arousal & Q21 & 0.722 & 11.123 & 0.001 & Confirmed \\
\hline & $\begin{array}{l}\text { Positive emotional } \\
\text { encouragement and } \\
\text { support }\end{array}$ & Q22 & 0.676 & 13.455 & 0.001 & \\
\hline
\end{tabular}




\begin{tabular}{|c|c|c|c|c|c|c|}
\hline & Modeling & Q23 & 0.631 & 12.552 & 0.001 & Confirmed \\
\hline & $\begin{array}{l}\text { Having career } \\
\text { capabilities }\end{array}$ & Q27 & 0.671 & 13.372 & 0.001 & Confirmed \\
\hline & Altruism & Q16 & 0.728 & 12.262 & 0.001 & Confirmed \\
\hline & Dynamic & & 0.749 & 12.525 & 0.001 & Confirmed \\
\hline & $\begin{array}{l}\text { organisational } \\
\text { structure }\end{array}$ & Q13 & & & & \\
\hline Organisational- & $\begin{array}{l}\text { Organisational mission } \\
\text { and performance }\end{array}$ & Q11 & 0.718 & 12.131 & 0.001 & Confirmed \\
\hline & Humility & Q15 & 0.676 & 11.593 & 0.001 & Confirmed \\
\hline & Job design & Q14 & 0.695 & 11.837 & 0.001 & Confirmed \\
\hline & Reward system & Q12 & 0.693 & 11.818 & 0.001 & Confirmed \\
\hline & Intuition & Q17 & 0.728 & 12.267 & 0.001 & Confirmed \\
\hline & Access to resources & Q10 & 0.620 & 11.235 & 0.001 & Confirmed \\
\hline & $\begin{array}{l}\text { Delegation of } \\
\text { authority }\end{array}$ & Q32 & 0.664 & 12.911 & 0.001 & Confirmed \\
\hline & $\begin{array}{l}\text { Delegation of } \\
\text { responsibility }\end{array}$ & Q33 & 0.677 & 13.146 & 0.001 & Confirmed \\
\hline & Information sharing & Q34 & 0.737 & 14.295 & 0.001 & Confirmed \\
\hline & Group belongingness & Q37 & 0.592 & 11.514 & 0.001 & Confirmed \\
\hline Managerial & $\begin{array}{l}\text { Guidance and } \\
\text { support }\end{array}$ & Q29 & 0.724 & 14.041 & 0.001 & Confirmed \\
\hline & Consulting & Q36 & 0.701 & 15.907 & 0.001 & Confirmed \\
\hline & Capacity building & Q35 & 0.708 & 14.524 & 0.001 & Confirmed \\
\hline & $\begin{array}{l}\text { Autonomous decision- } \\
\text { making }\end{array}$ & Q30 & 0.735 & 14.253 & 0.001 & Confirmed \\
\hline & $\begin{array}{l}\text { Participatory } \\
\text { management }\end{array}$ & Q31 & 0.753 & 14.591 & 0.001 & Confirmed \\
\hline & Meaningfulness & Q7 & 0.724 & 12.823 & 0.001 & Confirmed \\
\hline & Self-Determination & Q6 & 0.673 & 12.033 & 0.001 & Confirmed \\
\hline Psychological & Trust & Q8 & 0.710 & 12.603 & 0.001 & Confirmed \\
\hline & Competence & Q4 & 0.677 & 8.536 & 0.001 & Confirmed \\
\hline & Commitment & Q9 & 0.646 & 11.602 & 0.001 & Confirmed \\
\hline & Effectiveness & Q5 & 0.707 & 12.567 & 0.001 & Confirmed \\
\hline & $\begin{array}{l}\text { Motivational attitude } \\
\text { toward work }\end{array}$ & Q3 & 0.423 & 6.312 & 0.001 & Confirmed \\
\hline Confexfual & Doing teamwork & Q1 & 0.412 & 7.826 & 0.001 & Confirmed \\
\hline & Organisational culture & Q19 & 0.680 & 7.887 & 0.001 & Confirmed \\
\hline & Organisational climate & Q18 & 0.693 & 7.938 & 0.001 & Confirmed \\
\hline
\end{tabular}




\begin{tabular}{lll}
\hline FIT INDICES & OPTIMUM LEVEL & ESTIMATED LEVEL \\
\hline /df ${ }^{2} \chi$ & $3.00 \leq$ & 2.508 \\
\hline p-value & $0.05<$ & $0.001<$ \\
\hline GFI (Goodness of Fit Index) & $0.90 \geq$ & 0.900 \\
\hline RMSE (Root Mean Squared error) & $0.08 \leq$ & 0.060 \\
\hline IFI (Incremental Fit Index) & $0.90 \geq$ & 0.907 \\
\hline NFI (Normed Fit Index) & $0.90 \geq$ & 0.901 \\
\hline RFI (Relative Fit Index) & $0.90 \geq$ & 0.905 \\
\hline AGFI (Adjusted Goodness of Fit Index) & $0.90 \geq$ & 0.902 \\
\hline TLI (Tucker-Lewis Index) & $0.90 \geq$ & 0.906 \\
\hline CFI (Comparative Fit Index) & $0.90 \geq$ & 0.908 \\
\hline
\end{tabular}

\section{DISCUSSION AND CONCLUSION}

This research is a comprehensive study that has been conducted to investigate the factors affecting the empowerment of managers of health centres in Iran, to design a new model. The present study investigated the effect of the self-efficacy factor with indicators and components such as responsibility', using knowledge and managerial experiences, continuous training, challenging attitude toward working, having successful experiences, having professional skills, emotional arousal, positive emotional encouragement and support, modeling, and career capabilities; the psychological factor with components such as meaningfulness, personal determination and choice, trust, competence, commitment, and effectiveness; the managerial factor with components such as delegation of authority, responsibility, information sharing, group belongingness, guidance and support, counseling, capacity building, autonomous decision-making, and participatory management; the organisational-value factor with components such as dynamic organisational structure, organisational mission and performance, job design, reward system, access to resources, humility, altruism, and insight; and the contextual factor with components such as organisational culture, organisational climate, motivational attitude toward work, and doing teamwork on empowering health centre managers.
Regarding the self-efficacy factor affecting the empowerment of managers of health centres, the results of this study indicated the high impact of having professional skills. Various researchers have pointed out the importance of this in their studies. For instance, Robbins et al. [17] suggested that managers' technical, human, and cognitive skills are among the factors affecting their ability to perform better, which supports the results of the present study. Another finding of this study proved that "responsibility" is one of the most important components of the self-efficacy factor affecting the empowerment of health centre managers. In this regard, Konczak et al. [9], and Johnson [18], through their empowerment models, identified accountability as one of the effective elements of self-efficacy on employee empowerment. These results are in line with the results of the current research.

Concerning managerial components affecting the empowerment of managers of health centres, the findings of the present study showed that participatory management variable was of great importance in employee empowerment because of staff involvement in the decision-making process. Several researchers have reported the importance of this issue. According to Avolio et al. [19], leadership and management techniques in employee empowerment encourage them to think critically, engage in the decision-making process, and instill loyalty through understanding their mutual needs. They 
showed that participatory management and leadership plays an important role in employee empowerment. According to Lan \& Chong [20] with the psychological empowerment they do, transformational and participatory leaders significantly change employees' attitudes toward work and put them on the path to organisational effectiveness. According to Daft [21], participatory management provides the necessary framework for empowerment and adds depth and meaning to it through empowerment. The results of these studies are in line with those of the present study. Another finding of the present study is that the reduction in the organisation and increased staff empowerment has merged information sharing as one of the managerial components affecting the empowerment of managers of health centres. Randolph [22] presented three indicators for predicting human resource empowerment in the organisation, such as information sharing in the organisation, structural changes to reduce the focus on the organisation and increase employee empowerment, and organisational climate management, team building, and employee sharing Greasley et al. [5] showed that access to information is one of the pillars of employee empowerment. To this end, they must receive the information needed at the right time to make sensible decisions. This information should be easily accessible and quickly transmitted to the relevant staff. The results of these studies are in line with obtained results of present study.

Regarding the organisational-value components affecting the empowerment of health centre managers, the findings of the present study based on the results of CFA showed that the variable dynamic organisational structure was of high importance. Avolio et al. [19] believe that the closer the organisational structure is to the networked organisational structure where employees' autonomy is high, employees feel more competent and empowered. In empowerment, employees not only need authority but also need sufficient training, financial credibility, and information to be able to account for their decisions. According to the results of this study, humility and altruism are among the most important components of the organisational-value factor affecting the empowerment of health centre managers. Researchers see humility as one of the factors of employee empowerment. In their view, humility means not only to care for oneself but also to care for others, their abilities, and talents. [23] Altruism refers to helpful and beneficial behaviors such as intimacy, empathy, and compassion among colleagues that help employees with work problems, whether directly or indirectly, and promote empathy in the altruist. [24] According to Markoczy \& Xin [25], altruism has an impact on empowerment because it helps colleagues and employees perform their assigned tasks in a way beyond what is expected. The findings of these researchers confirm the results of the current study.

Concerning the psychological factor components affecting the empowerment of health centre managers, the findings of the present study revealed the high significance of meaningfulness. According to Liu et al. [26], Spreitzer [12], and Greasley et al. [5], meaningfulness means that an employee feels that he pursues important and valued career goals and moves on a road where his/her time and energy are precious. Lan \& Chong [20] believe that a sense of meaning comes from the proportion of one's job requirements, beliefs, values, and behaviours. Ideally, employees will understand the importance of their job to the organisation and themselves and will pay more attention to their work.

According to the results of this study, trust is one of the most important components of the psychological factor affecting the empowerment of managers of health centres. The results of Schermuly et al. [27] show that individuals' intragroup trust and relationships are effective in empowering and enhancing the capabilities of organisational individuals. According to Spreitzer [12], trust in others is a key element in interpersonal interactions; without it, alliance and cooperation neither forms nor sustains and empowered people trust others; they are confident that they will be treated fairly and honestly. They are confident that the authorities will treat them impartially. In other words, trust means having a sense of personal security and empowerment.[12] The obtained consequences of these researchers confirm the results of the present study.

Regarding the contextual factors affecting the empowerment of health centre managers, the findings of the present study showed that "organisational climate" was of great importance. Ekvall's [28] showed that organisational climate is a set of customs, traditions, beliefs, attitudes, and characteristics of the workplace that are perceived directly or indirectly by employees, and are a major force influencing the behavior of organisational employees. Mok \& Au-Yeung [29] studied the relationship between organisational climate and nursing empowerment in Hong Kong and showed a positive relationship between organisational climate and 
psychological empowerment. Based on the results of CFA, other findings identified organisational culture as one of the important elements of contextual factor empowerment of health centre managers. The results of Avernhammer \& Hall [30], showed the high importance of collaborative organisational culture. This culture requires members of the organisation to participate in affairs so that the organisation can meet the expectations of changing environmental factors which are in line with those of the present research.

Since no model has been presented to managers of health centres for utilizing the empowerment approach, the present study was able to induce factors and components affecting health centre managers' empowerment to executive processes through synergy in designing a model. To optimize the use of managers 'capacities and capabilities in the dynamic environment of health centres, access to a validated model (one of the factors influencing managers' empowerment in the health centre system) enables a picture of the prospects and future of health centres in achieving organisational goals. The model approved in this study has addressed the factors and components affecting the empowerment of health centre managers. The challenge for health centres is to understand the need to make good use of the intellectual resources, mental capacity, and potential of its managers, and to provide the appropriate framework for this. Given the impact of contextual, self-efficacy, managerial, organisational-value, and psychological factors on the final model validated in this study, senior health system managers can have a systemic approach to deal with these issues.

Besides, by utilising a continuous self-assessment system in health centres, applying the proposed model, improving administrative infrastructure, and working environment, paying attention to organisational culture, reward system, participatory management, information sharing, continuous training, and modeling, they can improve managers' abilities. To this end, it is recommended to establish some committees to empower human resources to utilize scientific methods and utilize the results of ongoing research and provide the framework for realizing this dynamically and actively. In this way, they can be suitably effective by utilizing a continuous self-assessment system to achieve the desired status. Also, the results of the present study can be used in communities with similar health systems to empower its human resources, especially the operational managers of health centres.

\section{LIMITATION OF THE STUDY}

The geographical distribution of the statistical population was one of the limitations of the present study, which was solved by managing the time of data collection.

\section{ACKNOWLEDGMENTS}

The authors express their gratitude to all the professors, specialists, administrators, and those who assisted the researchers in this study.

\section{CONFLICT OF INTEREST}

The authors declare that there was no conflict of interest.

\section{REFERENCES}

1. Yukl GA, Becker WS. Effective empowerment in organizations. Organizations management journal 2006; 3(3): 210-231.

2. Zhang $X, Y e H, L i$ Y. Correlates of structural empowerment, psychological empowerment and emotional exhaustion among registered nurses: A meta-analysis. Appl Nurs Res 2018; 42: 9-16.

3. Ellis JR, Hartley CL. Nursing in today's world: Trends, issues \& management. 10th ed. Philadelphia: Wolters Kluwer, Health/Lippincott Williams \& Wilkins; 2012.

4. Patrick AW, Laschinger HKS. The effect of structural empowerment and perceived organizational support on middle level nurse managers' role satisfaction. J Nurs Manag 2006; 14(1): 13-22.

5. Greasley K, Bryman A, Dainty ARJ, Price ADF, Naismith N, Soetanto R. Understanding empowerment from an employee perspective: What does it mean and do they want it? Team Perform Manag 2008; 14(1/2): 39-55.

6. Robbins TL, Crino MD, Fredendall LD. An integrative model of the empowerment process. Hum Resour Manage Rev 2002; 12(3): 419-443.

7. Bandura A. Self-Efficacy: The Exercise of Control. 1st ed. New York: W. H. Freeman publication; 1997.

8. Faulkner J, Laschinger $\mathrm{H}$. The effects of structural and psychological empowerment on perceived respect in acute care nurses. J Nurs Manag 2008; 16(2): 214-221 
9. Konczak LJ, Stelly DJ, Trusty MI. Defining and measuring empowering leader behaviors:

Development of an upward feedback instrument. Educ Psychol Meas 2000; 60(2): 301-313.

10. Kuokkanen L, Katajisto J. Promoting or impeding empowerment? Nurses' assessments of their work environment. JONA, J Nurs Adm 2003; 33(4): 207-217.

11. Vogt JF, Murrell KL. Empowerment in Organizations How to Spark Exceptional Performance. Calif.: University Associates, San Diego; 1990.

12. Spreitzer GM. Psychological empowerment in the workplace: Dimensions, measurement, and validation. Academy of Management Journal 1995; 38(5): 14421465.

13. Mallak LA, Kurstedt HA. Understanding and using empowerment to change organizational culture. Industrial Management 1996; 38(6): 8-40.

14. Melhem Y. The antecedents of customer-contact employees' empowerment. Employee Relations 2004; 26(1): 72-93.

15. Cho J, Laschinger HK, Wong C. Workplace empowerment, work engagement and organizational commitment of new graduate nurses. Nursing Leadership- Academy of Canadian Executive Nurses (Toronto, Ont.) 2006; 19(3): 43-60.

16. Eskandari M. Designing an empowerment system model for managers. Journal of Humanities Teacher 2004; 8(2): 53-80.

17. Robbins SP, De Cenzo DA, Coulter MA. Fundamentals of Management: Essential Concepts and Applications. 9th ed. England: Pearson publication; 2017.

18. Johnson MO. The shifting landscape of health care: Toward a model of health care empowerment. Am J Public Health 201 1; 101 (2): 265-270.

19. Avolio BJ, Gardner WL, Walumbwa FO, Luthans F, May DR. Unlocking the mask: A look at the process by which authentic leaders impact follower attitudes and behaviors. Leadersh Q 2004; 15(6): 801-823. Avolio BJ, WL Gardner, FO Walumbwa, F Luthans and DR May

20. Lan XM, Chong WY. The mediating role of psychological empowerment between transformational leadership and employee work attitudes. Procedia Soc Behav Sci 2015; 172(1): 184191.

21. Daft RL. The Leadership Experience. 6th ed. Boston: Cengage Learning publication; 2014.
22. Randolph WA. Educating part-time MBAs for the global business environment. J Coll Teach Learn 2008; 5(8): 11-18.

23. Dennis R, Bruce E. A factor analysis of page and Wong's servant leadership instrument. Leadership \& Organization Development Journal (LODJ) 2003; 24(7/8): 455-459.

24. Biswas S. Affective commitment as a mediator between psychological climate, job involvement and citizenship behavior. Management and Laboure Studies. 2008; 33(4): 22-32.

25. Markoczy L, Xin K. The Virtues of Omission in Organizational Citizenship Behavior. USA: University of California; 2004.

26. Liu Y, Wang W, Chen D. Linking ambidextrous organizational culture to innovative behavior: A moderated mediation model of psychological empowerment and transformational leadership. Front Physiol 2019; 10: 2192.

27. Schermuly CC, Meyer B, Dammer L. LeaderMember exchange and innovative behavior the mediating role of psychological empowerment. J Pers Psychol 2013; 12(3): 132.

28. Ekvall G. Organizational climate for creativity and innovation. EUR J WORK ORGAN PSY 1996; 5(1): 105123.

29. Mok E, Au-Yeung B. Relationship between organizational climate and empowerment of nurses in Hong Kong. J Nurs Manag 2002; 10(3): 129-137.

30. Auernhammer J, Hall H. Organizational culture in knowledge creation, creativity and innovation: Towards the freiraum model. J INF SCI 2014; 40(2): 154166. 